\title{
Comparison of diurnal dynamics in evaporation rate between bare soil and moss-crusted soil within a revegetated desert ecosystem of northwestern China
}

\author{
Ya-Feng Zhang, Xin-Ping Wang*, Yan-Xia Pan and Rui Hu \\ Shapotou Desert Research and Experiment Station, Cold and Arid Regions Environmental and Engineering \\ Research Institute, Chinese Academy of Sciences, Lanzhou 730000, China. \\ ${ }^{*}$ Corresponding author.e-mail: zyfr7759961@163.com
}

\begin{abstract}
Effects of biological soil crusts (BSCs) on soil evaporation is quite controversial in literature, being either facilitative or inhibitive, and therein few studies have actually conducted direct evaporation measurements. Continuous field measurements of soil water evaporation were conducted on two microlysimeters, i.e., one with sand soil collected from bare sand dune area and the other with moss-crusted soil collected from an area that was revegetated in 1956, from field capacity to dry, at the southeastern edge of the Tengger Desert. We mainly aimed to quantify the diurnal variations of evaporation rate from two soils, and further comparatively discuss the effects of BSCs on soil evaporation after revegetation. Results showed that in clear days with high soil water content (Day 1 and 2), the diurnal variation of soil evaporation rate followed the typical convex upward parabolic curve, reaching its peak around midday. Diurnal evaporation rate and the accumulated evaporation amount of moss-crusted soil were lower (an average of 0.90 times) than that of sand soil in this stage. However, as soil water content decreased to a moderately low level (Day 3 and 4), the diurnal evaporation rate from moss-crusted soil was pronouncedly higher (an average of 3.91 times) than that of sand soil, prolonging the duration of this higher evaporation rate stage; it was slightly higher in the final stage (Day 5 and 6) when soil moisture was very low. We conclude that the effects of moss crusts on soil evaporation vary with different evaporation stages, which is closely related to soil water content, and the variation and transition of evaporation rate between bare soil and moss-crusted soil are expected to be predicted by soil water content.
\end{abstract}

\section{Introduction}

Water is the principal limiting factor in determining the structure, composition and function of desert ecosystems (Noy-Meir 1973; Aguiar and Sala 1999). Thereof, evaporation is the key process in water balance and hydrologic cycle (Laity 2009), through which water losses can amount to $50 \%$ or more of precipitation (Hillel 1998). Evaporation is mainly affected by biological soil crusts (BSCs) and plant cover and composition in desert ecosystems
(Belnap et al. 2005). BSCs are communities of diminutive but important organisms that may include lichens, mosses, liverworts, cyanobacteria and others, which are intimately associated with soil particles, creating a cohesive thin horizontal layer (Belnap 2003; Bowker 2007; Li 2012). BSCs can profoundly influence the hydrologic regimes of arid and semi-arid desert ecosystems, including infiltration patterns, run off, dew formation and soil water retention (Belnap 2006; Li et al. 2010; Coppola et al. 2011).

Keywords. Biological soil crusts; soil evaporation; diurnal variation; bare soil; moss-crusted soil. 
BSCs are the dominant living cover in vast drylands of the world (Belnap 2006). As reported by St. Clair et al. (1993), BSCs occupy $40-100 \%$ of the ground cover in an area with relatively sparse vascular plant cover. Evaporation from BSCs is thus a significant component in hydrologic cycle, and also in eco-hydrological modelling. It is, however, quite controversial in literature concerning the effects of BSCs on soil evaporation. Some authors believe that BSCs can increase soil evaporation, while others favour a decrease. The former argument is mainly supported by the following facts: (1) BSCs darken soil surface, and have a relatively lower albedo, increasing soil surface temperature and further evaporative loss (Johansen 1993; Belnap and Lange 2002; Belnap 2006; Kidron and Tal 2012); (2) BSCs can retain more water at soil surface for evaporation due to their high water retention (West 1990; Chamizo et al. 2013); (3) BSCs increase surface roughness and thus surface area for potential evaporation (Belnap et al. 2005). The latter argument is mainly supported by the swelling of exopolysaccharides in BSCs and the association of BSCs with clay and silt cap the soil surface, clog soil pores and impeding evaporative loss (Brotherson and Rushforth 1983; Verrecchia et al. 1995; Kidron et al. 1999; Belnap et al. 2005; Fischer et al. 2010). In addition, previous studies on evaluating the evaporation from BSCs mostly lacked of direct measurements, and therein the diurnal variation of soil evaporation rate was also little quantified under field conditions. As such, direct comparative investigations relating to the effects of BSCs on soil evaporation under field conditions are called for.

The objective of this study was to quantitatively evaluate the effects of BSCs on diurnal evaporation rate by continuous comparative measurements on the evaporation of two microlysimeters, i.e., one with sand soil collected from bare sand dune area and the other with moss-crusted soil collected from an area that was revegetated in 1956, from field capacity to dry under field conditions. The current study is also expected to be helpful for a better understanding of revegetation efforts on soil evaporation variations in arid and semi-arid regions.

\section{Material and methods}

\subsection{Site information}

The study was conducted at the Shapotou Desert Research and Experiment Station (SDRES) of Chinese Academy of Sciences $\left(37^{\circ} 32^{\prime} \mathrm{N}, 105^{\circ} 02^{\prime} \mathrm{E}\right.$, an elevation of $1300 \mathrm{~m}$ a.s.l.), located at the southeastern fringe of the Tengger Desert in northwestern
China. Mean annual precipitation is $191 \mathrm{~mm}$ (1955-2005, SDRES) with $80 \%$ of rain occurring between July and September. The groundwater is deep around 50-80 $\mathrm{m}$ and it is unavailable for plant roots. Dew formation and water adsorption on soil surface are assumed to be a minor water source (Pan et al. 2010). Mean maximum air temperature is $24.7^{\circ} \mathrm{C}$ in July and mean minimum is $-6.1^{\circ} \mathrm{C}$ in January. Potential evapotranspiration is approximately $2500 \mathrm{~mm}$ during the growing season, resulting in a large annual moisture deficit. The area is surrounded by relatively plain interdunes and free from any disturbances of grazing, fire and wood chopping. The dune sand mainly consists of fine Typic Psammaquents sand (0.05-0.25 mm) with a clay content of about $0.2 \%$ (Berndtsson et al. 1996).

To protect the Baotou-Lanzhou railway against encroaching sand dunes in the Shapotou area, a $16,000 \mathrm{~m}$ long $(500 \mathrm{~m}$ width to the north and $200 \mathrm{~m}$ to the south) artificially revegetated protection system was established along the BaotouLanzhou railway, after the revegetation efforts in the 1950-1980s, done mainly by setting up of straw checkerboards in the moving sand soil and planting xerophytic shrubs (mainly C. korshinskii, H. scoparium and A. ordosica) within them. A detailed description of the revegetation procedure of study area can be found in Li et al. (2006). The former sand dune landscape has been greatly transformed into a landscape characterized by a mosaic of the sparse shrubs and herbs and the bare interspaces covered with BSCs of different development stages (Li et al. 2006).

\subsection{Soil column collection and pre-processing}

Two types of soil were chosen for experiments: bare sand soil from a moving sand dune area (figure 1a) and the well-developed and undisturbed moss-crusted soil from an area that was revegetated in 1956 (figure 1b). Moss dominated BSCs have a deep green colour in wet conditions and a brown colour in dry conditions (Zhang et al. 2014). The thickness of moss crusts of the chosen area was $1.92 \mathrm{~cm}$ measured by a vernier caliper. The properties of these two soils, including particle size distribution, bulk density and organic matter can be referred in Zhang et al. (2014).

For intact soil columns collection, a $30 \times 30 \mathrm{~cm}$ surface area of each soil was artificially wetted to a depth of at least $20 \mathrm{~cm}$. After that, a cylindrical polyvinyl chloride (PVC) microlysimeter $(19.4 \mathrm{~cm}$ inner diameter and $13 \mathrm{~cm}$ height) was gently vertically inserted into each soil profile. Soils around the outer surface of microlysimeter were removed, and afterwards, a rectangle iron plate with a sharp end was horizontally inserted along the bottom of 

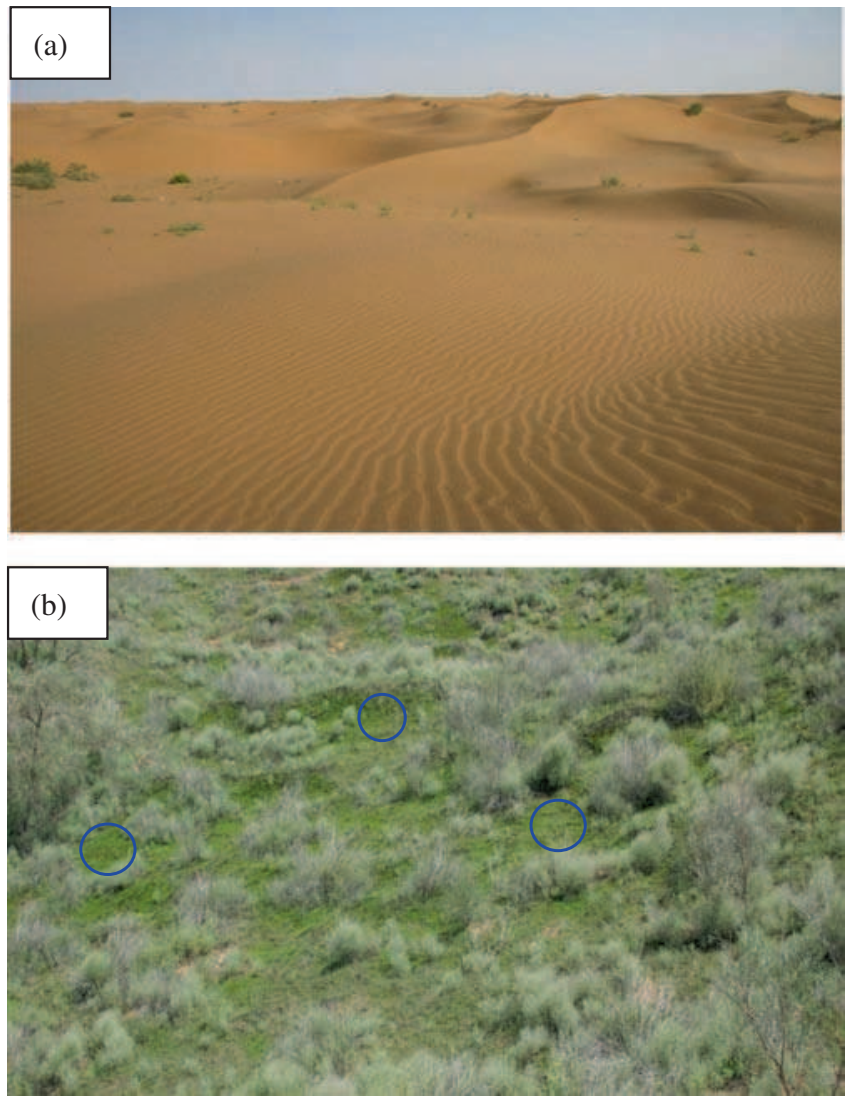

Figure 1. General view of (a) sand dunes and (b) a revegetation enclosure that was established in 1956 at study site. Moss-dominated biological soil crust patches are exemplified in blue circles in (b).

the microlysimeter. The microlysimeter was then carefully excavated from the soil, and the base was wrapped with two layers of fine mesh gauze which allows free water migration but not soil particles. Two microlysimeters (one with bare soil and the other with moss-crusted soil) were then taken back to the laboratory for saturation and drainage.

Before starting the evaporation measurements, each soil column was gradually and thoroughly saturated through bottom, using tap water on a ceramic plate in a basin, and then subjected to drainage for $12 \mathrm{hr}$ during night until excess water was drained. This ensures the two soil columns attaining the similar initial conditions for subsequent evaporation measurements.

\subsection{Soil evaporation measurements and calculation}

Soil evaporation measurements were carried out between September 2 and 7, 2014 (hereafter Day 1 to 6$)$ at SDRES. The sand soil microlysimeter and the moss-crusted soil microlysimeter were placed on a Sartorius CPA34001S and a Sartorius LA1$6001 \mathrm{~S}$ electronic balance (precision: $\pm 0.1 \mathrm{~g}$; scale size: $40 \times 30 \mathrm{~cm}$ ), respectively, for consecutive mass weighing in the open field. Each microlysimeter was encircled by an outer PVC ring of the same height to prevent soil column from solar heating through the walls of the microlysimeters. The distance between two balances was around $30 \mathrm{~cm}$. Data were automatically recorded using a Campbell 1000 data logger (Campbell Corporation, CA, USA) with a frequency of $30 \mathrm{~min}$. Soil evaporation amount $(\mathrm{mm})$ was calculated by the water loss $(\mathrm{g})$ and the cross-sectional area $\left(\mathrm{cm}^{2}\right)$ of microlysimeter. Soil evaporation rate $\left(\mathrm{mm} \mathrm{h}^{-1}\right)$ was expressed as the ratio of evaporation amount to time.

Once the field evaporation measurements were finished, two microlysimeters were taken back to the laboratory, and soil columns were dried in an oven at $105^{\circ} \mathrm{C}$ for $72 \mathrm{hr}$. Gravimetric water content of each column was calculated as the ratio of water mass to the mass of dry soil.

\subsection{Meteorological variables}

Incoming solar radiation, air temperature, relative humidity and wind speed at $2 \mathrm{~m}$ were measured every $30 \mathrm{~s}$, and 30-min averages were recorded by an automatic weather station with a Delta-T Logger (Delta-T device Ltd, UK).

\section{Results}

\subsection{Meteorological parameters}

Day 1-4 were typical clear days and Day 5-6 were cloudy days, which can also be inferred from the diurnal variations of solar radiation of corresponding days (figure 2a). Diurnal variations of air temperature, wind speed and relative humidity are also shown in figure 2 , with an average of $19.6^{\circ} \mathrm{C}$ for air temperature, $1.1 \mathrm{~m} \mathrm{~s}^{-1}$ for wind speed and $18.6 \%$ for relative humidity.

\subsection{Soil water content and evaporation amount}

Having undergone exactly the same processing during saturation and subsequent drainage, mosscrusted soil had a higher water content (28.6\%) than sand soil $(23.2 \%)$, suggesting a higher water retention of moss-crusted soil.

Soil water content in two microlysimeters, exclusively had a rapid decrease during daytime of Day 1-4 (figure 3a), while this was inappreciable during nocturnal time (from 21:00 to 8:00 of the following day). Soil water content attained a lower level (3.8\% for sand soil and 5.8\% for moss-crusted soil) after consecutive evaporation loss in microlysimeters during Day 1-4. In Day 5 and 6, variations 

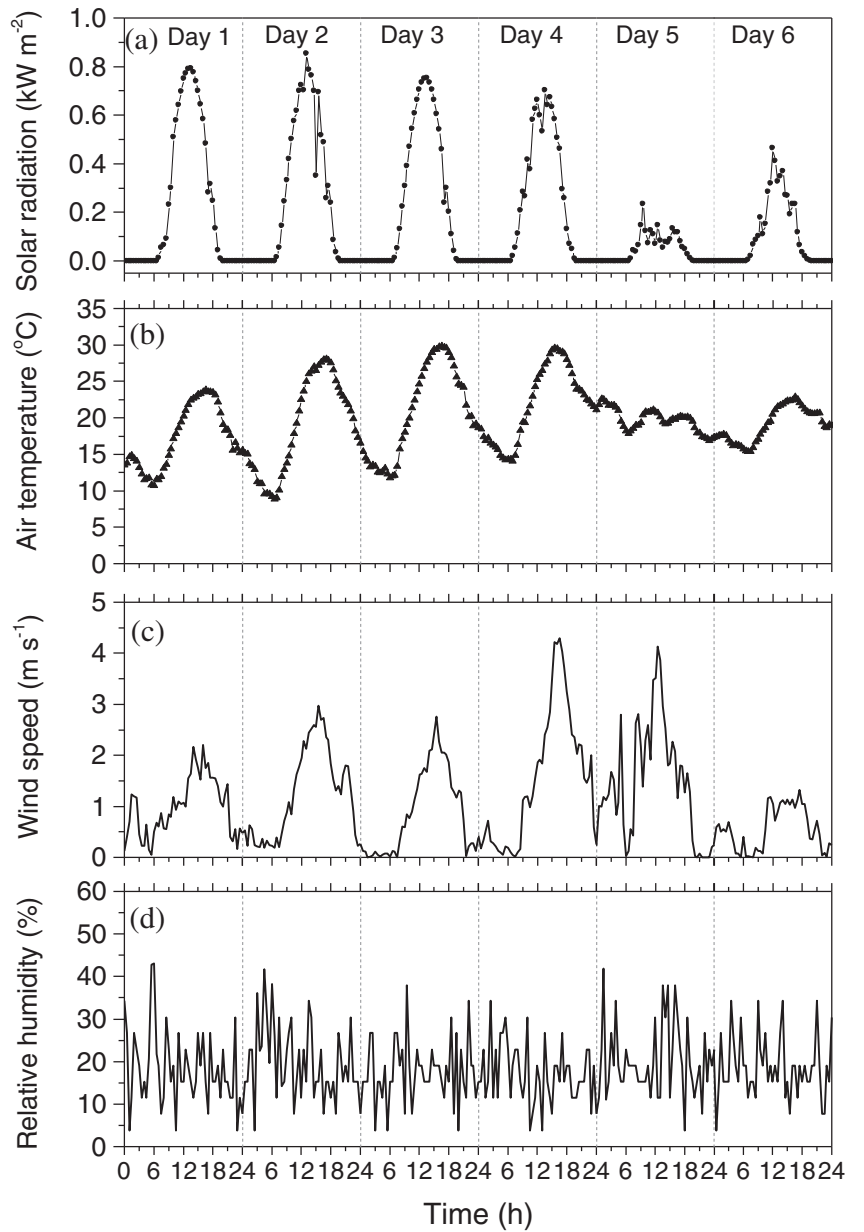

Figure 2. Diurnal variations of (a) solar radiation, (b) air temperature, (c) wind speed and (d) relative humidity during experimental period.

in soil water content were inconspicuous. The initial difference $(y)$ in soil water content between two soils was $5.4 \%$, being higher in moss-crusted soil than in sand soil (figure $3 \mathrm{~b}$ ); this value increased and attained its peak around 08:30 of Day 3, and then started to sharply decrease, and fell back to $5.4 \%$ at $17: 00$ of Day 3 ; it dropped to $1.57 \%$ by the end of the experiment.

Daily soil evaporation amount decreased as evaporation measurements continued, and a higher value was observed in sand soil than in mosscrusted soil in the initial evaporation stage (Day 1 and 2) (figure 4), which can also be observed from a comparison of the variation of accumulated evaporation amount between two microlysimeters (figure 5). However, evaporation amount decreased sharply for sand soil and moderately for mosscrusted soil starting from Day 3, and moss-crusted soil, in turn, began to have a higher evaporation amount than sand soil (figure 4). Concerning the period between 08:30 and 20:30 in daytime, the evaporation amount for moss-crusted soil was 10.96 (Day 1), 10.05 (Day 2), 8.19 (Day 3), 5.38 (Day 4)

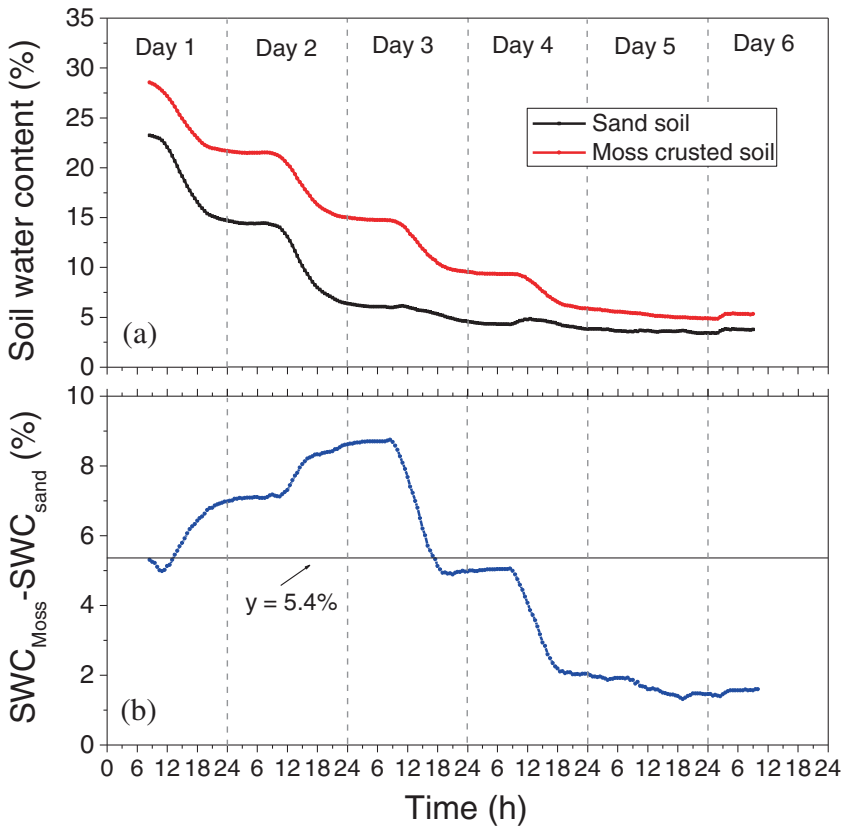

Figure 3. Soil water content (a) and its difference (b) between moss-crusted soil ( $\left.\mathrm{SWC}_{\mathrm{Moss}}\right)$ and sand soil ( $\left.\mathrm{SWC}_{\mathrm{Sand}}\right)$ during experimental period. $\mathrm{y}=5.4 \%$ is the initial difference in soil water content between two soils.

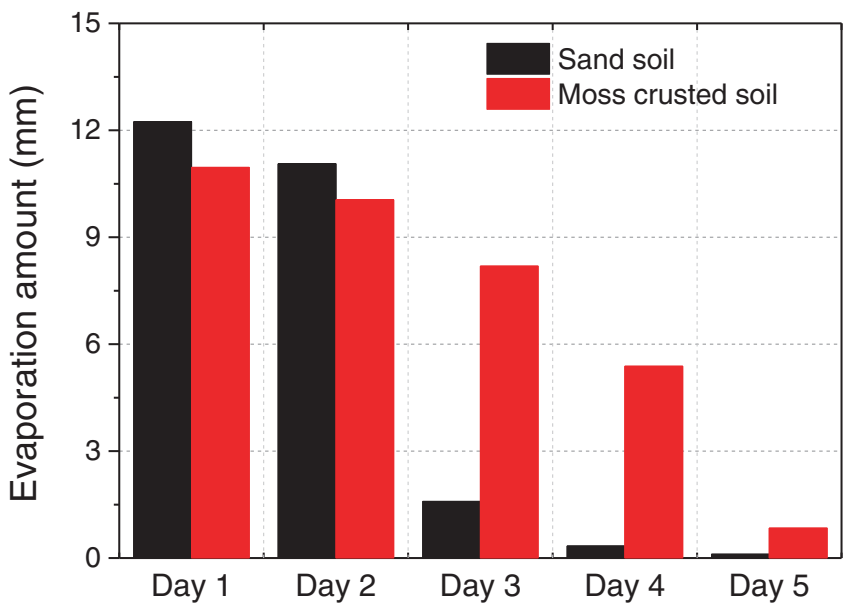

Figure 4. Comparison of evaporation amount between sand soil and moss-crusted soil during each experimental day.

and $0.84 \mathrm{~mm}$ (Day 5), respectively. The corresponding values for sand soil were: 12.24 (Day 1), 11.06 (Day 2), 1.59 (Day 3), 0.34 (Day 4) and $0.11 \mathrm{~mm}$ (Day 5). By the end of the experiment, the accumulated evaporation amount was 39.2 and $30.2 \mathrm{~mm}$ for moss-crusted soil and sand soil, respectively (figure 5).

\subsection{Variations of soil evaporation rate}

Diurnal curves of soil evaporation rate from two microlysimeters are shown in figure 6. In Day 1 


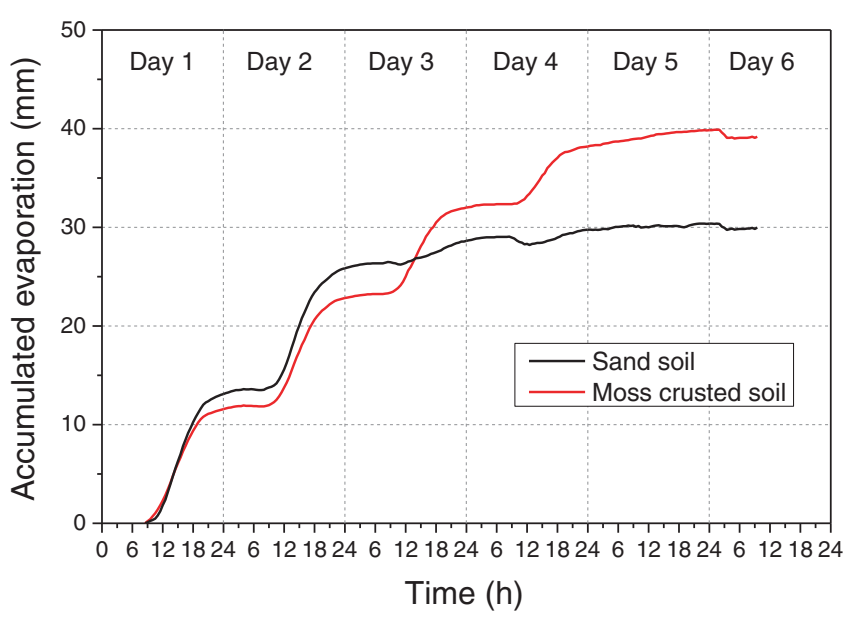

Figure 5. Accumulated evaporation amount vs. time for sand soil and moss-crusted soil.

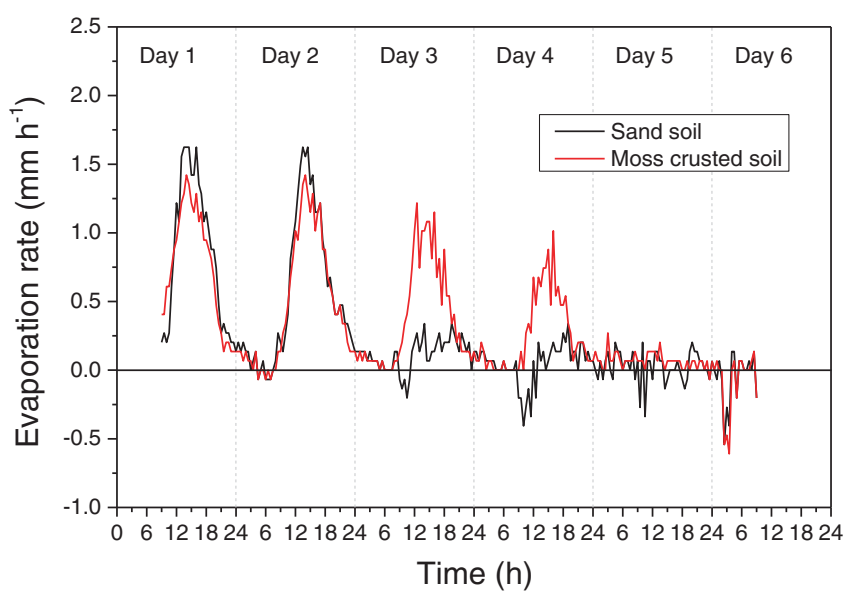

Figure 6. Comparison of evaporation rate vs. time between sand soil and moss-crusted soil.

and 2, both showed a convex upward parabolic curve, attaining its peak around 14:00, and the diurnal evaporation rate from sand soil was higher than that of moss-crusted soil. For instance, at 13:30 of Day 2, the evaporation rate from sand soil amounted to $1.62 \mathrm{~mm} \mathrm{~h}^{-1}$, and it was $1.35 \mathrm{~mm} \mathrm{~h}^{-1}$ for moss-crusted soil. On an average, evaporation rate from moss-crusted soil was 0.90 times lower than that of sand soil. In Day 3 and 4, the diurnal evaporation rate was moderately lower for moss-crusted soil and sharply lower for sand soil compared to the previous two days. In contrast, moss-crusted soil began to show a distinctly higher diurnal curve than sand soil. On an average, the evaporation rate from moss-crusted soil was 3.91 times higher than that of sand soil. In Day 5 and 6 , the evaporation rate was rather low for both soils. Meanwhile, it should be noted that negative values of evaporation rate were observed in the nocturnal time.

\section{Discussion}

Our study area experienced a long-term artificial revegetation, which transformed the former landscape with bare and homogeneous moving sand dunes into the stable landscape characterized by a mosaic of the sparse shrubs and herbs and the interspaces covered by BSCs (e.g., figure 1; Li et al. 2006, 2007). BSCs of this area generally occurred in the sequence of 'Algae crusts, algae-lichen crusts, lichen crusts, lichen-moss crusts and moss crusts' (Li et al. 2010; Lan et al. 2012). So what happened to the soil evaporation from sand soil to moss-crusted soil? Our results indicated that when soil water content was in a high level (Day 1 and 2 , the initial stage), evaporation rate from mosscrusted soil was averagely 0.90 times lower than that of sand soil (figure 6), though moss-crusted soil had a higher initial water content than sand soil (figure 3). Since two soil microlysimeters had undergone exactly the same treatment in saturation and subsequent drainage before conducting evaporation measurements, a higher initial water content in moss-crusted soil implies a higher water retention than in sand soil. In fact, it has been experimentally evidenced by Coppola et al. (2011) and Wang et al. (2013), at the same study area, that the moss-crusted soil after sand dune stabilization is more structured than the original sand soil and thus keeps a relatively higher water retention and lower hydraulic conductivity than the sand soil. This also indicates that after the presence of BSCs and during its gradual colonization and development, the underlying soil properties such as particle size distribution and soil organic matter were somewhat changed. This has been evidenced by Li et al. (2007) and Wang et al. (2007) who showed that the proportions of fine particles and soil organic matter increased, because soil texture and organic matter are considered as the dominant factors affecting soil water retention (Hillel 1998). However, as soil water content proceeded to a moderately low level (Day 3 and 4, the middle stage), evaporation rate from moss-crusted soil, in turn, began to exceed that of sand soil and maintained for a relatively long duration (figure 6), suggesting that moss-crusted soil with thick and high-biomass crusts prolongs the time, water can be kept on or at the soil surface, thus contributing to a greater evaporation rate. On an average, evaporation rate from moss-crusted soil was 3.91 times higher than that of sand soil in this stage. The differences in water retention and the hydraulic conductivity between two soils (Coppola et al. 2011), by determining the evaporation behaviour, may well be used to explain the higher evaporation amount (figure 4) and rate (figure 6) in the mosscrusted soil than in sand soil observed in this stage, 
and eventually the higher accumulated evaporation amount by the end of experiments (figure 5). Note that the higher water retention in moss-crusted soil does not necessarily increase evaporation rate in the initial stage (which mostly depends on the atmospheric demand) but prolongs the duration of its high evaporation rate in the middle stage. In addition, a dry layer was probably formed at the beginning of middle stage at bare sand soil surface which greatly decreases subsequent water vapour transport from soil into atmosphere; however, moss crusts prevent the formation of this dry soil layer, resulting in a greater water loss on the moss-crusted soil for a longer time. In the final evaporation stage (Day 5 and 6 ), soil water content was very low and the diurnal cycles of evaporation rate from two soils were subtle. This is partially due to the low soil water content caused by large evaporation loss in the previous four days (figure 3a) and partially due to lower solar radiation in the two cloudy days (figure 2a). The impact of BSCs on soil water evaporation is quite controversial in the literature, being either facilitative (West 1990; Belnap 2006; Kidron and Tal 2012; Chamizo et al. 2013) or inhibitive (Brotherson and Rushforth 1983; Kidron et al. 1999; Liu et al. 2007), and therein, few studies have conducted direct evaporation measurements. Liu et al. (2007) conducted an indoor rainfall simulation experiment to evaluate the effects of BSCs on soil evaporation at Shapotou area using a microlysimeter $(10 \mathrm{~cm}$ in diameter and $30 \mathrm{~cm}$ in height). He concluded that for lower rainfall $(<7.5 \mathrm{~mm})$, BSCs act to retard evaporation processes; when subjected to greater rainfall amounts $(>10 \mathrm{~mm})$, however, the crusted surfaces started to show favourable effects on evaporation rate. Our results are somewhat contradictory with Liu et al. (2007). Our evaporation measurements were carried out under natural field conditions with varying evaporativity, while Liu et al. (2007) conducted indoor measurements under constant evaporativity which disregarded the effects of complex meteorological factors, in particular, the diurnal variations of soil radiation on soil evaporation. The different experimental settings (indoor and field conditions) probably explain the contrasting results, as suggested by Kidron and Tal (2012) who reviewed that researchers who focussed on laboratory experiments on soil evaporation tended to attribute a positive role to the BSCs, while those examining the BSCs under field conditions tended to attribute a negative role to the BSCs. Nevertheless, our findings are similar to Xiao et al. (2010) from 'wind-water erosion criss-cross' region on the Loess Plateau of China, that BSCs decrease soil evaporation rate significantly $(P<0.01)$ at the beginning and prolong the duration of high evaporation rate stage. Moreover, Chamizo et al.
(2013) found that when soil moisture was moderately low (11\%), evaporation was slightly higher in well-developed BSCs than in physical crusts or poorly-developed BSCs, and while at low soil moisture $(<6 \%)$, there was no difference in evaporation among crust types or the underlying soils.

Soil evaporation amount and rate are mainly determined by energy and water regimes in soils (Allen et al. 1998; Hillel 1998). Our results showed that sand soil and moss-crusted soil exclusively had the typical diurnal curves of evaporation rate in clear days, when the soil water were sufficient (Day 1 and 2), which also corresponds well with diurnal variations of incoming solar radiation (figure $2 \mathrm{a}$ ), suggesting that evaporation rate mostly depends on the atmospheric demand in this stage. According to Allen et al. (1998), this stage can thus be regarded as energy limiting stage: the evaporation from soil exposed to the atmosphere limited by energy availability at the soil surface. This stage holds until water in soils cannot be transported to the surface at a rate that can supply the potential demand (Allen et al. 1998). While, when soil water content was in a lower level (Day 3-6), the evaporation rate was evidently reduced. We considered this stage as falling rate stage, where soil evaporation decreases proportionally to the amount of water remaining in surface soil layer (Allen et al. 1998), i.e., this stage is mostly limited by water regimes in soils. In the present study, it should be noted that we also observed negative values of soil evaporation rate in certain time periods (figure 6). We assume that this is mainly attributable to the minor but consistent and stable dew formation and water absorption at the surfaces of bare sand and moss crust in the nocturnal time (Liu et al. 2006; Pan et al. 2010), and meantime the dew amounts were higher than the very low evaporative loss during these periods.

In the present study, we only compared the evaporation difference between sand soil and mosscrusted soil, thus only highlighting the difference in soil evaporation before revegetation and after some years of revegetation, when BSCs had succeeded to its moss-crust dominated stage. Though there is a large difference between potential evapotranspiration and precipitation (resulting in a large soil moisture deficit) in our study area, the conversion of moving sand into soil surface dominated by BSCs is sustainable on its own under rain-fed conditions (Li et al. 2007; Li 2012). From the viewpoint of evaporation, our results suggest that the moisture deficit may not be significantly changed by BSCs, while BSCs may play a positive role in sustaining itself, as well as, shallow-rooted annuals by enhancing soil water retention. Since our study area was revegetated in different years, i.e., 1956, 1964, 1976 and 1982, this well-established 
chronological sequence enables us to have a detailed understanding on the evaporation of BSCs in different development stages and further the dynamic influences of revegetation on soil evaporation during the succession, and this thus merits further researches.

\section{Conclusion}

After a long-term revegetation at our study area, soil water evaporation dynamics have been changed from sand soil to moss-crusted soil. Our results indicate that sand soil had a higher evaporation than moss-crusted soil in the initial stage (Day 1 and 2), when soil water was abundant. This, however, turned into the opposite in the middle stage (Day 3 and 4), as soil water content proceeded to a moderately low level. As a whole, moss-crusted soil decreased evaporation in the initial stage, and sustained a high evaporation in the middle stage. Nevertheless, the accumulated evaporation was greater in moss-crusted soil than in sand soil by the end of the experiment because of a higher water content due to its higher water retention. We conclude that the variation and transition of evaporation rate between bare soil and moss-crusted soil are expected to be predicted by soil water content.

\section{Acknowledgements}

This study was supported by the State Key Program of National Natural Science Foundation of China (41530750), the National Natural Science Foundation of China $(41501108,41371101)$ and the CAS "Light of West China" Program. We appreciate the Associate Editor and three anonymous reviewers for their constructive comments.

\section{References}

Aguiar M R and Sala O E 1999 Patch structure, dynamics and implications for the functioning of arid ecosystems; Trends Ecol. Evol. 14(7) 273-277.

Allen R G, Pereira L S, Raes D and Smith M 1998 Crop evapotranspiration - Guidelines for computing crop water requirements-FAO irrigation and drainage paper 56; FAO, Rome 300 D05109 144-146.

Belnap J 2003 The world at your feet: desert biological soil crusts; Front. Ecol. Environ. 1(4) 181-189.

Belnap J 2006 The potential roles of biological soil crusts in dryland hydrologic cycles; Hydrol. Process. 20(15) 3159-3178.

Belnap J and Lange O L 2002 Biological soil crusts: structure, function, and management; Springer, Berlin, Germany.
Belnap J, Welter J R, Grimm N B, Barger N and Ludwig J A 2005 Linkages between microbial and hydrologic processes in arid and semi-arid watersheds; Ecology 86(2) 298-307.

Berndtsson R, Nodomi K, Yasuda H, Persson T, Chen H S and Jinno K 1996 Soil water and temperature patterns in an arid desert dune sand; J. Hydrol. 185(1-4) 221-240.

Bowker M A 2007 Biological soil crust rehabilitation in theory and practice: An underexploited opportunity; Restor. Ecol. 15(1) 13-23.

Brotherson J D and Rushforth S R 1983 Influence of cryptogamic crusts on moisture relationships of soils in Navajo National Monument, Arizona; Great Basin Nat. 43(1) 73-78.

Chamizo S, Canton Y, Domingo F and Belnap J 2013 Evaporative losses from soils covered by physical and different types of biological soil crusts; Hydrol. Process. 27(3) 324-332.

Coppola A, Basile A, Wang X P, Comegna V, Tedeschi A, Mele G and Comegna A 2011 Hydrological behaviour of microbiotic crusts on sand dunes: Example from NW China comparing infiltration in crusted and crustremoved soil; Soil Till. Res. 117 34-43.

Fischer T, Veste M, Wiehe W and Lange P 2010 Water repellency and pore clogging at early successional stages of microbiotic crusts on inland dunes, Brandenburg, NE Germany; Catena 80 47-52.

Hillel D 1998 Environmental soil physics: Fundamentals, applications and environmental considerations; Academic Press, London, UK.

Johansen J R 1993 Cryptogamic crusts of semi-arid and arid lands of North America; J. Phycol. 29(2) 140-147.

Kidron G J and Tal S Y 2012 The effect of biocrusts on evaporation from sand dunes in the Negev Desert; Geoderma 179 104-112.

Kidron G J, Yaalon D H and Vonshak A 1999 Two causes for runoff initiation on microbiotic crusts: Hydrophobicity and pore clogging; Soil Sci. 164(1) 18-27.

Laity J J 2009 Deserts and desert environments; John Wiley \& Sons, Chichester, UK.

Lan S B, Wu L, Zhang D L and Hu C X 2012 Successional stages of biological soil crusts and their microstructure variability in Shapotou region (China); Environ. Earth Sci. 65(1) 77-88.

Li X R 2012 Eco-hydrology of biological soil crusts in desert regions of China; Higher Education Press, Beijing (in Chinese).

Li X R, Xiao H L, He M Z and Zhang J G 2006 Sand barriers of straw checkerboards for habitat restoration in extremely arid desert regions; Ecol. Eng. 28(2) 149-157.

Li X R, Kong D S, Tan H J and Wang X P 2007 Changes in soil and vegetation following stabilisation of dunes in the southeastern fringe of the Tengger Desert, China; Plant Soil 300(1-2) 221-231.

Li X R, Tian F, Jia R L, Zhang Z S and Liu L C 2010 Do biological soil crusts determine vegetation changes in sandy deserts? Implications for managing artificial vegetation; Hydrol. Process. 24(25) 3621-3630.

Liu L C, Li S Z, Duan Z H, Wang T, Zhang Z S and Li X R 2006 Effects of microbiotic crusts on dew deposition in the restored vegetation area at Shapotou, northwest China; J. Hydrol. 328(1-2) 331-337.

Liu L C, Song Y X, Gao Y H, Wang T and Li X R 2007 Effects of microbiotic crusts on evaporation from the revegetated area in a Chinese desert; Soil Res. 45(6) $422-427$.

Noy-Meir I 1973 Desert ecosystems: Environment and producers; Ann. Rev. Ecol. Syst. 4 25-51.

Pan Y X, Wang X P and Zhang Y F 2010 Dew formation characteristics in a revegetation-stabilized desert 
ecosystem in Shapotou area, northern China; J. Hydrol. 387(3-4) 265-272.

St. Clair L L, Johansen J R and Rushforth S R 1993 Lichens of soil crust communities in the intermountain area of the western United States; Great Basin Nat. 53(1) 5-12.

Verrecchia E, Yair A, Kidron G J and Verrecchia K 1995 Physical properties of the psammophile cryptogamic crust and their consequences to the water regime of sandy soils, north-western Negev Desert, Israel; J. Arid Environ. 29(4) 427-437.

Wang X P, Quan G J, Pan Y X, Hu R, Zhang Y F, Tedeschi A, Basile A, Comegna A, Coppola A and Mascellis R 2013 Comparison of hydraulic behaviour of unvegetated and vegetation-stabilized sand dunes in arid desert ecosystems; Ecohydrology 6 264-274.
Wang $\mathrm{X} \mathrm{P}$, Young $\mathrm{M} \mathrm{H}$, Yu Z, Li X $\mathrm{R}$ and Zhang Z S 2007 Long-term effects of restoration on soil hydraulic properties in revegetation-stabilized desert ecosystems; Geophys. Res. Lett. 34(24) L24S22, doi: 10.1029/2007GL031725.

West N E 1990 Structure and function of microphytic soil crusts in wildland ecosystems of arid to semi-arid regions; Adv. Ecol. Res. 20 179-223.

Xiao B, Zhao Y G and Shao M A 2010 Characteristics and numeric simulation of soil evaporation in biological soil crusts; J. Arid Environ. 74(1) 121-130.

Zhang Y F, Wang X P, Hu R, Pan Y X and Zhang H 2014 Variation of albedo to soil moisture for sand dunes and biological soil crusts in arid desert ecosystems; Environ. Earth Sci. 71(3) 1281-1288. 